\title{
Supporting Pharmaceutical Healthcare Outreach
}

\section{A Culminating First-Year Programming Experience}

\author{
John K. Estell \\ ECCS Department \\ Ohio Northern University \\ Ada, Ohio, USA \\ j-estell@onu.edu
}

\author{
Stephany Coffman-Wolph \\ ECCS Department \\ Ohio Northern University \\ Ada, Ohio, USA \\ s-coffman-wolph@onu.edu
}

\author{
Jessica Sieg \\ College of Pharmacy \\ Ohio Northern University \\ Ada, Ohio, USA \\ j-sieg@onu.edu
}

\author{
Michelle Musser \\ College of Pharmacy \\ Ohio Northern University \\ Ada, Ohio, USA \\ m-musser@onu.edu
}

\begin{abstract}
Although they might initially think otherwise, students can make positive societal impacts through their programming skills, even as early as their introductory programming courses. This paper describes a culminating first-year experience where student programming teams are paired with clients majoring in a doctor of pharmacy program to develop software applications in support of the clients' community-focused educational outreach activities on the hazards involving the use of electronic cigarettes. In the process, the programming students are exposed to various concepts beyond the expected coverage of technical competencies, focusing on ways to deliver meaningful value to others from an entrepreneurial mindset perspective. Positive feedback and data gathered from student surveys, course evaluations, alumni emails, and client comments indicates that, through this service-learning focused term project, programming students learn valuable software development and personal communication skills that will carry them beyond this course and into their professional lives. To assist those who are interested in implementing this project at their institution, adoption materials are available without charge via download from the Engineering Unleashed information repository.
\end{abstract}

\section{CCS CONCEPTS}

- Software and its engineering $\rightarrow$ Software creation and management $\rightarrow$ Designing software; Applied computing $\rightarrow$ Education $\rightarrow$ Interactive learning environments; - Applied computing $\rightarrow$ Life and medical sciences $\rightarrow$ Consumer health.

\section{KEYWORDS}

Client; Entrepreneurial Mindset; Project-Based Learning; Programming; Service-Learning; Teamwork.

Permission to make digital or hard copies of all or part of this work for personal or classroom use is granted without fee provided that copies are not made or distributed for profit or commercial advantage and that copies bear this notice and the full citation on the first page. Copyrights for components of this work owned by others than the author(s) must be honored. Abstracting with credit is permitted. To copy otherwise, or republish, to post on servers or to redistribute to lists, requires prior specific permission and/or a fee. Request permissions from Permissions@acm.org.

SIGCSE '21, March 13-20, 2021, Virtual Event, USA.

(C) 2021 Copyright is held by the owner/author(s). Publication rights licensed to ACM. ACM ISBN 978-1-4503-8062-1/21/03...\$15.00

https://doi.org/10.1145/3408877.3432470

\section{ACM Reference format:}

John K. Estell, Stephany Coffman-Wolph, Jessica Sieg, and Michelle Musser. 2021. Supporting Pharmaceutical Healthcare Outreach: A Culminating First-Year Programming Experience. In Proceedings of the 52nd ACM Technical Symposium on Computer Science Education (SIGCSE '21), March 13-20, Virtual Event. ACM, New York, NY, USA, 7 pages. https://doi.org/10.1145/3408877.3432470

\section{Motivation and Related Work}

A former student, explaining her decision to change her major, left a note on the back of her CS1 midterm that concluded as follows: "I don't see how I can make a difference in the lives of others by sitting behind a computer screen." Thus began nearly a decade of research, looking at ways to incorporate elements of the entrepreneurial mindset into the introductory programming experience that focuses on delivering value for others.

As defined by Engineering Unleashed [1], there are three key elements associated with entrepreneurial mindset instruction. First, students should be empowered to investigate opportunities in a rapidly changing world via curiosity. Curiosity is a trait worth promoting; for example, one of the ACM Retention Committee's recommendations for retaining students in computer science is to give them a better understanding of computing by building courses around compelling context that draws one's attention [2]. Second, by habitually pursuing knowledge, students gain insight into potentially innovative solutions when connections are made between discoveries and other sources of information. Capstone projects have been used to directly involve students in information gathering by providing multiple opportunities for customer and community interactions [3], where the value of possessing proper communication skills usually becomes readily apparent to the students [4]. Third, by pursuing solutions in ways that incorporate and subsequently harmonize the needs and demands of various stakeholders, students learn about creating value for others. Many students, like the one mentioned earlier, want to make a difference by helping others; using socially-relevant projects can provide students with an affirming experience [5]. While such servicelearning projects have usually been conducted either as part of software engineering or senior project (i.e., capstone) courses, cases have been made for conducting them as "cornerstone" projects - culminating course term projects during the first-year $[6,7]$. By emphasizing the concepts of curiosity, connections, and creating value through the use of a project focused on providing 
service to a real-world client, first-year programming students learn that they are not coding for themselves but are designing for others by addressing their problems. In this way, we as computer science instructors can help illustrate the positive impacts of computing through projects containing compelling, sociallyrelevant context.

\section{Project Context}

The introductory programming sequence at Ohio Northern University (ONU) consists of two 4-semester credit courses, each consisting of three 50-minute lectures plus a 165-minute laboratory session each week for 15 weeks. Programming 1 is offered in the fall term, focusing on using $\mathrm{C}++$ to implement small programs exercising concepts in sequence, selection, and iteration. Programming 2 is offered in the spring, using Java to introduce the object-oriented paradigm, graphical user interfaces, and eventdriven programming. This course sequence is required for all ONU students majoring in either computer science or computer engineering, along with those students pursuing a computer science minor, and is normally taken in the first year.

The term project begins in earnest after students return from Spring Break, providing eight weeks for its completion; however, team formation and building exercises occur earlier in the semester. Teams of 3-4 students are formed primarily on the basis of schedule availability through the use of CATME Team-Maker software [8], whereupon they use CATME resources to create team charters for planning the interactions, goals, and strategies for completing tasks in preparation for their first teaming experience: developing a simplified variation of the Oregon Trail educational simulation game. Both CATME and team charters are familiar concepts, having been introduced in the Foundations of Design 1 course that all first-year students in the college are required to take in their first semester. Besides being used to "stress test" each team, this preliminary activity introduces two critical concepts. The NABC (Need, Approach, Benefits, Competition) method [9] provides teams with a systematic approach to creating a value proposition, allowing them to craft a message containing ideas derived from an analysis of the problem being addressed. After the successful pitching of a proposal, teams implement just enough features of the proposal - a Minimum Viable Product (MVP) [10] - such that a working prototype is available for soliciting client feedback. Traditionally, the Oregon Trail assignment ends with the MVP demonstration. Students then use CATME to rate teamwork performance through both self and peer evaluations [11], followed by a SWOT (Strengths, Weaknesses, Opportunities, and Threats) analysis, also previously introduced in the Foundations course, so that the team's strengths and weaknesses are discussed before working on the project.

\section{Prior Research}

Initial efforts (2011 through 2013) in Programming 2 focused on having student teams write educational games in Java aligning to the State of Ohio's Academic Content Standards. Teams were constrained by an assigned grade level but were allowed to select their design's academic content area, standard, and benchmark. In addition to the developed applications, project deliverables included problem identification statements, oral and written final reports, and a video demonstrating the application. While this gave students an appreciated freedom of choice with their problem selection, the lack of a client with an application in mind precluded students from having authentic learning experiences. To address this critical issue, in Spring 2014 the course partnered with a group of ONU faculty and students developing continuing education workshop modules for teachers in the Dominican Republic [12], where programming teams augmented alreadydeveloped lesson plans by writing GUI-based software applications [13].

While the Programming 2 students attained tangible benefits from their indirect participation in the associated service-learning activity [14], annual service trips to the Dominican proved financially unsustainable. Additionally, assessment results uncovered multiple shortcomings, including insufficient clientteam interactions, unrealistic project scope, and no performance of needs analysis. Thus, for 2015 the project was revised: creating software applications in support of lesson plans used in the ONU College of Engineering's educational outreach efforts, with a concerted effort made to incorporate the entrepreneurial mindset into the development process. Assessment results indicated that statistically significant improvements in student attitudes were attained [15].

Subsequent Programming 2 cohorts included clients from ONU's early childhood, middle childhood, and engineering education programs. A retrospective study conducted in 2018 further validated the successfulness of the collaborative approach between first-year programming students and upper-level education majors [16]. Unfortunately, steadily increasing computer science enrollments combined with decreasing enrollments in all areas of education at ONU made the continuation of this model tenuous at best, with the 2019 course offering requiring the participating education majors and the instructors to serve as clients for multiple teams. Clearly, to maintain the benefits that the introductory programming students were receiving, further revisions were needed.

\section{A New Client}

Kappa Psi, founded in 1879, is the largest professional pharmaceutical fraternity in the United States, with over 6,000 students and 87,000 alumni members [17]. Many of the collegiate chapters, including ONU's, are co-educational. Members of Kappa Psi engage in educational outreach activities at various local community events, commonly interacting with people through the use of a tri-fold poster board and associated handouts.

In May 2019, the Outreach Chair for ONU's Kappa Psi chapter contacted the computer science program regarding creating a software application with multimedia elements to enhance and extend their outreach efforts on informing middle and high school students in Hardin County on the dangers of using electronic cigarettes (e-cigarettes), i.e., vaping. Of particular concern was elaborating on the health risks associated with adolescent vaping; 
data reported in the 2018 National Youth Tobacco Survey [18] indicated that e-cigarette use among middle and high school students increased alarmingly between 2017 and 2018, with over 3.6 million kids reported using e-cigarettes in 2018. According to the Centers for Disease Control and Prevention, the various hazards associated with vaping include nicotine addiction, exposure to cancer-causing chemicals and heavy metals, adverse mental development, the potential for chronic obstructive pulmonary disease, and even explosions and fires caused by defective or damaged e-cigarette batteries [19].

Ten Kappa Psi members, all students in the Doctor of Pharmacy program at ONU, served as clients for the Spring 2020 offering of Programming 2. Each Kappa Psi member worked with one team of introductory programming students. To help constrain development efforts, teams were assigned to design for end users in one of two possible target populations: either 7th grade (middle school) or 10th grade (high school) students. As part of the client-provided problem statement, programming students were made aware of the possibility that their application would be utilized at all five school districts in the county, plus at community events targeting adolescents, including $4-\mathrm{H}$ programs and local girls' groups. At a minimum, teams were asked to include coverage of the following: first nicotine exposure, e-cigarette use in daily life, and effects of continued e-cigarette use.

\section{Process}

\subsection{Meeting the Client}

Programming 2 students receive the project upon their return from spring break and are asked to read the one-page problem statement before attending their first class back. An in-class exercise is then used to help prepare for meeting the client in lab the next day. First, students are individually asked some simple questions on the meeting preparation process, and are then prompted to reflect on three key points: "what you would do to be prepared and professional for the initial meeting," "what questions would you most like to have answered during the meeting," and "what pleasing qualities do you have to offer the client." After recording their individual responses, the team then collaboratively analyzes their responses, classifying them into tasks to be performed either before, during, or after the meeting. Students are then provided with the Client Meeting Checklist [20], which identifies, according to research conducted with practicing professionals, those key performance objectives to be attained before, during, and after a meeting. Engaging in these "three intelligences" [sic] - individual, collaborative, and collective - helps to both affirm and inform their efforts, thereby promoting team cohesion, greater buy-in, and student ownership of the meeting preparation process [21]. Teams use the results from this activity to prepare an agenda for their client meeting. Once the clients arrive the next day during the scheduled laboratory session, teams are temporarily dismissed so that their meetings can be conducted in more accommodating venues, such as huddle rooms and collaboration spaces.

\subsection{Preparations and Proposals}

Before jumping into the design process, programming students are exposed to the concept of Interactive Learning Events - a collective term encompassing the use of games, gamification, and simulations in educational activities. This content provides students with a set of user-oriented design constraints for focusing their design efforts on topics such as what benefits will be provided to the students using their software application, how the features of their app will affect the students' learning, and what students will feel when experiencing app-based learning.

Upon reviewing the materials and information provided at the initial meeting and conducting subsequent research, possibly with follow-up client meetings, each team applies the user story mapping approach, which envisions how representative users interact with a product, to develop two sufficiently differentiated informal project proposals presenting possible app ideas. These submissions are then reviewed through the application of the Project Proposal Rubric by a committee formed by clients and associated engineering and pharmacy faculty members. Submitting two preliminary proposals allow the reviewers greater flexibility in providing feedback (for example, recommending combining elements from both proposals) while providing student teams with some insurance, as the odds of both proposals being poorly received are rather high. Based on the committee's input, each client provides feedback to their team. Next, teams use the Project Proposal Template to write a formal design proposal, using the rubric feedback in developing the specifications of a single application. The NABC method is employed at this stage to identify salient design features and create a value proposition. Additionally, the MVP process is used to scope the app's infrastructure to determine what critical elements need to be implemented first to allow for client engagement feedback. Documents containing the proposal, the NABC pitch, and the MVP specifications are all submitted for review; following both instructor and client approval, teams move forward with software development.

It is worth noting that Ohio Northern University converted to a fully remote instruction mode due to the COVID-19 pandemic the day after holding the initial client meetings. Aside from roughly one week of instruction subsequently lost due to various transitioning activities, the use of online collaborative meeting tools, such as Google Meet and Miro, successfully replaced the planned in-person meetings, allowing the project to continue.

\subsection{Progress Reports and Reviews}

To provide the teams with proper guidance, a combination of progress reports and design reviews are used during development. The instructional goal for this phase is to provide formative feedback, by whatever means, at least once a week. To assist the teams, two additional tools are now provided. The Software Application Evaluation Rubric uses the single-point format [22] to provide feedback on the aesthetics, usability, comprehension, performance, engagement, and learning dimensions of the application. The expected performance standards are stated, with checkboxes allowing the rating of each dimension to be classified 
as either demonstrating "mastery," "proficiency," "developing," or "lacking" in that particular trait. A "comments" field allows the reviewer to provide qualitative feedback for each dimensional rating. Students are also provided with a Weekly Progress Report Template similar to the one used in the college's capstone courses. This report is used to summarize all work individually performed for the prior week, indicate what problems the team is currently facing, steps being taken in trying to address the issues involved, and outline each team member's planned activities for the coming week. While sometimes viewed as "mindless paperwork," such reports do provide for accountability within the team and allows an instructor to readily discern where the discussion needs to be focused during team meetings, or if an intervention is needed due to performance issues.

Weekly review meetings alternate between teams meeting with their client and with the course instructors, with the schedule set such that teams perform their MVP design review with their client. Teams use the Client Meeting Checklist in preparation for client meetings and submit a Weekly Progress Report in preparation for instructor meetings. This combination allows the team to regularly obtain feedback on both technical and topical matters. Teams are also encouraged to reach out as needed whenever any questions requiring external resolution arise.

\subsection{App Fair}

In previous offerings of Programming 2, an "App Fair" - similar in concept to a science fair - was held on the same day as the department's industrial advisory board meeting. With course instructors serving as moderators, several reviewing rounds of approximately 15 minutes in length were held, allowing teams to interact one-on-one with a variety of judges drawn from industry, alumni, and faculty in obtaining a critical design review of their project one week before the deadline. A team member recorded the judges' oral comments, and each judge separately filled out a Software Application Evaluation Rubric for each evaluated group.

Although the COVID-19 pandemic precluded conducting the App Fair in its traditional format, it was easily transitioned into an online event. To recruit judges, the course instructors reached out to engineering faculty, pharmacy faculty, and members of the Kappa Psi professional fraternity; additionally, the Dean of the college contacted department alumni across the country who work in software development and are approximately 10-15 years removed from graduation. Teams host a Google Meet room for three 20- to 25-minute sessions scheduled 30 minutes apart; the extra time allows judges to fill out the Software Application Evaluation Rubric and get to their next session. Teams start each session by providing an NABC-framed presentation on their project to a group of judges, followed by a demonstration of their application. The remainder of the session serves as discussion time, allowing judges to probe more deeply into the team's design. To provide quick feedback, the evaluation rubric is implemented in Google Forms, allowing the results to be shared shortly after the App Fair's conclusion. These results are also used by the instructors and clients following product delivery as one of the metrics for determining which completed apps to deploy as part of Kappa Psi's educational outreach efforts.

\subsection{Final Steps and Deliverables}

The primary deliverable for the project is a JAR file containing the deployable version of the client's Java application. To accomplish this, a few final steps are necessary. The feedback from the App Fair is used as input to a variation of the MVP process, where teams now determine, given the time constraints arising from nearing the semester's end, what suggested modifications can be completed, which ones might be doable if any additional time remains, and those which are either non-essential or are too complex to be attempted. This new MVP document now serves as a road map towards project completion.

As one of the remaining deliverables is an oral presentation, teams were allowed to meet the requirement this year by recording one of their App Fair's Google Meet sessions. These recordings enabled the instructors to evaluate the oral presentations asynchronously, focusing on assessing that portion containing the NABC presentation. While traditional in-class oral presentations allow for peer-based learning experiences by students seeing other teams' implementations, asking this year's students to watch still more videos after two months of online instruction was not deemed pedagogically sound. The remaining deliverables included teams submitting their app's project folder containing their source code, turning in their NABC presentation slides, and performing both peer evaluations and self-reflection on team performance.

\section{Results}

Pharmacy is a profession that focuses on improving the quality of life for individuals. Accordingly, service-learning is an integral component of the student experience in the ONU College of Pharmacy, where one of the graduation requirements involves participating in at least 50 hours of community engagement activities such as health risk screenings and public health education. This provides pharmacy majors with various insights into serving as a health care professional. Much of the outreach is performed by the college's student organizations, such as Kappa Psi; students desiring a more in-depth experience have the option of taking the college's Introduction to Service Learning course, where students are paired with a community agency interested in developing or expanding their outreach programming.

To test the hypothesis that, by working with clients directly involved with service-learning projects, the programming students would obtain some of the benefits associated with servicelearning, the Community Service Attitude Scale (CSAS) survey was chosen as the assessment instrument [23]. Containing 46 questions utilizing a 7-point Likert scale, where 1 represents "strongly disagree" or "extremely unlikely" and 7 represents "strongly agree" or "extremely likely," the survey assesses 10 student attitudes dimensions: awareness of community needs, perception of actions that can meet the need, perceiving one's ability to help, one's sense of connectedness to one's community that motivates helping, one's sense that personal or situational norms obligate one to help, one's sense of empathy for those in need, both the costs and the benefits to oneself of helping, beliefs about the seriousness of the consequences of not helping others, 
and one's intentions to engage in community service [24]. Table 1 compares data collected from the current student cohort with that previously reported in the literature using the same CSAS instrument [23, 24, 25, 26], including data collected at ONU from 2014 to 2017 as part of a four-year research study [16].

Changing clients to Kappa Psi Pharmaceutical Fraternity and supporting their middle school and high school outreach efforts successfully maintained the students' views and attitudes on service-learning. The 2020 data compares favorably to both data collected from previous offerings of the Programming 2 course (the second set of four columns, denoted by course year) and data found in the literature (the first set of four columns, denoted by references to the papers reporting that information). It is worth noting that the 2020 data from both the Moral Obligation and Reassessment phases (with perceived costs going down while the other two dimensions scoring higher) indicate that students are slightly more receptive to this combination of client and project. Unfortunately, at the time of this writing, the client has not been able to deploy the apps selected for use in their educational outreach activities, due to Special Orders enacted by the Ohio Department of Health prohibiting mass gatherings; however, the client is sufficiently pleased with the results that they have agreed to collaborate on a similar project with the Spring 2021 Programming 2 class.

\section{Student Reflections and Lessons Learned}

Anyone who taught in the spring of 2020 can attest that it was an unprecedented experience, one full of constant uncertainty. However, despite the pandemic, the programming students gained essential skills from participating in this service-oriented term project. Through post-activity surveys, students cited that the project's most beneficial aspect was teamwork and coding as a group; specifically, students appreciated learning the skill of dividing out work and then combining it back together. One student noted that "working with teammates helped me actually prepare for the future," and alluded to the results of the preliminary assignment and subsequent SWOT analysis, indicating that it was helpful "knowing what default strengths and weaknesses to expect in team-based environments." Given the predominantly (but unplanned) online nature of the project, it was serendipitous that learning about teamwork in a software development environment was one of the foci of this project.

The students also provided many positive comments on working with a client and feeling that the project was a "realworld" application. Having a client was seen as very beneficial, as one student wrote that they were "working on a more open-ended assignment" where "nothing was predefined other than do what the client wants." Another student opined that the open-ended nature of the project "gave you the ability to be creative." Multiple students stated thoughts similar to the following quote: "I really enjoyed working in a team alongside with a client, I think it was a nice real-world situation." One student, who mentioned that their father is employed as an IT manager at a major insurance company, wrote that "while I did not particularly enjoy these assignments that much overall, I did talk to my dad a few times about the course and he thought that the things that we were being introduced to was very beneficial." Additionally, the students provided favorable comments regarding the Minimum Viable Product approach to software development, with one stating that it allowed the team "to get feedback without having to put too much work into the program just to have the client say that he or she doesn't like it..." while another student mentioned that "it is easy to get in over your head with all the details," thus "it really pays off to take a step back and just look at the necessities." The App Fair also received its share of positive comments, the most interesting being from its use as a critical design review: "I loved the feedback from the judges. I think it really helped us make the project exponentially better than it really was!"

As part of the survey, students were invited to suggest changes for improving future offerings of the term project. While most students felt the format of the project did not require major modifications, those suggestions received focused primarily on

TABle 1. Post-Activity CSAS Student AtTitudes Paired with those Reported in the Literature.

\begin{tabular}{|l||c|c|c|c||c|c|c|c|c|}
\hline 7-point Likert Scale & {$[\mathbf{2 3}]$} & {$[\mathbf{2 4}]$} & {$[\mathbf{2 5}]$} & {$[\mathbf{2 6}]$} & $\mathbf{2 0 1 4}$ & $\mathbf{2 0 1 5}$ & $\mathbf{2 0 1 6}$ & $\mathbf{2 0 1 7}$ & $\mathbf{2 0 2 0}$ \\
\hline 7 = "strongly agree" $\quad \boldsymbol{n =}$ & 332 & 77 & 78 & 17 & 22 & 23 & 21 & 31 & 30 \\
\hline Phase 1: Perceptions & & & & & & & & & \\
\hline Awareness & 6.21 & 6.23 & 5.68 & 6.27 & 5.80 & 6.17 & 5.95 & 6.12 & 6.06 \\
\hline Actions & 5.61 & 5.66 & 5.30 & 6.07 & 5.81 & 6.14 & 5.82 & 5.78 & 5.89 \\
\hline Ability & 5.42 & 5.26 & 5.27 & 5.95 & 5.59 & 5.64 & 5.71 & 5.54 & 5.79 \\
\hline Connectedness & 5.02 & 5.10 & 4.70 & 5.57 & 5.11 & 5.42 & 5.24 & 5.09 & 5.36 \\
\hline Phase 2: Moral Obligation & & & & & & & & & \\
\hline Norms & 6.03 & 5.92 & 5.71 & 6.17 & 5.71 & 5.93 & 5.73 & 5.88 & 6.05 \\
\hline Empathy & 5.61 & 5.59 & 5.00 & 5.75 & 5.67 & 5.61 & 5.51 & 5.55 & 5.73 \\
\hline Phase 3: Reassessment & & & & & & & & & \\
\hline Costs & 4.46 & 4.84 & 2.78 & 4.67 & 5.38 & 5.35 & 5.20 & 5.24 & 4.97 \\
\hline Benefits & 5.67 & 5.81 & 5.24 & 6.05 & 5.57 & 5.61 & 5.47 & 5.56 & 5.61 \\
\hline Seriousness & 4.82 & 4.79 & 4.47 & 5.15 & 5.19 & 5.17 & 4.87 & 4.72 & 5.23 \\
\hline Phase 4: Helping & 4.95 & 4.99 & 4.61 & 5.50 & 5.09 & 5.28 & 4.83 & 4.84 & 5.21 \\
\hline
\end{tabular}


having more training on software collaboration tools, such as Git and Trello, and on providing additional guidance regarding client interactions. Some students saw little value in the SWOT analysis, with one stating "if I had a team that didn't want to work it really wouldn't have mattered if we completed a SWOT or not." Other remarks concerned the varying timeline of the project. Unfortunately, the class time lost due to COVID as students scrambled to leave campus starting the day after the initial client meeting, plus converting all aspects of the course, including its project, to a remote learning environment, required scheduling changes that had a compressive effect on the rest of the term project schedule. When compared to prior years, this resulted in leaving less time for teams to implement the changes recommended by judges during the App Fair. These comments were atypical from prior years, and primarily a product of the pandemic, but do raise the point that care needs to be taken with the project timeline. However, some comments occur without fail every year, such as criticizing that the course was overly focused on "business" content and should focus more on programming content, and that the course involved significantly more work than any of their other courses while not realizing that this course has an additional credit hour accounting for that effort.

\section{Faculty Reflections and Lessons Learned}

The instructors felt the project overall went well, despite the pandemic-induced upheaval, an opinion reinforced by the positive survey results received. Advanced planning is important; work began during the Fall 2019 semester, with a total of four one-hour meetings held roughly on a monthly basis between the instructors and representatives from Pharmacy and the Kappa Psi Pharmaceutical Fraternity, with the final meeting held just prior to spring break. These meetings covered such topics as developing the problem statement, recruiting client participants, and reviewing the client-team operational structure. As time for students to meet with their clients was incorporated into their laboratory schedule, client-team assignments were made based on a client's availability to meet with teams in either the morning or afternoon laboratory session. Overall, the relationships forged amongst the parties involved allowed the client-team partnership to easily pivot to a remote instruction environment without major consequences.

Having to move the App Fair online fortuitously exposed a previously untapped opportunity. Distance was no longer an issue: instead of relying solely on those living close enough to physically attend an advisory board meeting, the instructors could invite alumni from across the country to participate. Thus, students were able to have their projects judged by software professionals working at well-known corporations such as Amazon, Microsoft, and SpaceX. Several of these alumni contacted the course instructors afterward, expressing their thanks for being asked to participate, offering additional advice, and volunteering their services for future App Fairs. From this success, future iterations of this project will incorporate a code review near the time of the App Fair where teams will meet electronically with alumni as part of a software quality assurance activity.

\section{Available Resources and Adoption Tips}

The authors strongly believe that experiential reports should provide the means for interested readers to readily implement items of interest. To help facilitate such adoptions, the CSaffiliated authors have created a "Card" - i.e., an information repository - for this paper on the Engineering Unleashed website [27]. This card provides additional details regarding the project outlined in this paper, along with all of the resources developed for this project, including handouts developed "in-house" such as the Client Interaction Checklist, Project Proposal Template, and Software Application Evaluation Rubric. Additional instructional materials are provided for covering the MVP process and the NABC method. This repository of artifacts can be freely downloaded, reviewed, adopted, and if desired modified, by anyone for use in computer science or other disciplines for courses oriented towards design.

While this paper has focused on a collaboration with those involved with health care educational outreach efforts, the procedures and techniques described here can by readily applied to other educational outreach and/or engagement efforts, such as in STEM. Additionally, on-campus clients tend to be easier to approach, carry lesser risk due to the emphatic nature of working with other students, and makes the scheduling of client-team meetings more feasible.

\section{Conclusion}

Teams of introductory programming students worked with pharmacy clients in addressing their educational outreach needs, and in so doing participated in a service-learning experience while creating value for members of the community. Concepts such as the Minimum Viable Product, and tools such as the NABC method, allowed each team to develop and present ideas to their client early on, thereby allowing them to readily assess whether they were on the right track toward a usable product. Similarly, the App Fair provided students with the opportunity to receive meaningful feedback on their work from practicing professionals in both the software development and pharmaceutical healthcare areas. This project also allowed students to showcase what they had learned from a technical standpoint, and its relatively openended scope provided an opportunity for creativity, subject to the constraints of the client's needs. Students were successful in incorporating elements of the entrepreneurial mindset into a cornerstone project culminating their introductory programming coursework, thereby making a difference in the lives of others while sitting behind a computer screen.

\section{ACKNOWLEDGMENTS}

The proposal for this study, entitled "Educational Game Construction - Service Learning Research," was granted exempt review status by the Institutional Review Board (IRB) of Ohio Northern University under protocol \#JE-EN-012218-1.

This work was made possible in part by the generous support of the Kern Family Foundation's KEEN (Kern Entrepreneurial Engineering Network) program. 


\section{REFERENCES}

[1] The Kern Family Foundation. 2020. Welcome to Engineering Unleashed. Retrieved from https://engineeringunleashed.com

[2] Chris Stephenson, Alison Derbenwick Miller, Christine Alvarado, Lecia Barker, Valerie Barr, Tracy Camp, Carol Frieze, Colleen Lewis, Erin Cannon Mindell, Lee Limbird, Debra Richardson, Mehran Sahami, Elsa Villa, Henry Walker, and Stuart Zweben. 2018. Retention in Computer Science Undergraduate Programs in the U.S.: Data Challenges and Promising Interventions. Association for Computing Machinery, New York, NY, USA.

[3] Ruth E. Anderson, Gaetano Borriello, Helene Martin, and Leonard Black. 2009. Capstone Projects as Community Connectors. Fournal of Computing Sciences in Colleges 25, 1 (2009), 116-122.

[4] Joseph Mertz and Scott McElfresh. 2010. Teaching Communication, Leadership, and the Social Context of Computing via a Consulting Course. In Proceedings of the 41st ACM Technical Symposium on Computer Science Education (SIGCSE '10). Association for Computing Machinery, New York, NY, USA, 77-81. https://doi.org/10.1145/1734263.1734291

[5] Michael Buckley, Helene Kershner, Kris Schindler, Carl Alphonce, and Jennifer Braswell. 2004. Benefits of Using Socially-Relevant Projects in Computer Science and Engineering Education. SIGCSE Bulletin 36, 1 (March 2004), 482-486. https://doi.org/10.1145/1028174.971463

[6] Mary Anne L. Egan and Mathew Johnson. 2010. Service Learning in Introductory Computer Science. In Proceedings of the Fifteenth Annual Conference on Innovation and Technology in Computer Science Education (ITiCSE '10). Association for Computing Machinery, New York, NY, USA, 812. https://doi.org/10.1145/1822090.1822095

[7] Saquib Razak. 2013. A Case for Course Capstone Projects in CS1. In Proceedings of the 44th ACM Technical Symposium on Computer Science Education (SIGCSE '13). Association for Computing Machinery, New York, NY, USA, 693-698. https://doi.org/10.1145/2445196.2445398

[8] Richard A. Layton, Misty L. Loughry, Matthew W. Ohland, and George D. Ricco. 2010. Design and Validation of a Web-Based System for Assigning Members to Teams using Instructor-Specified Criteria. Advances in Engineering Education 2, 1 (2010), 1-28.

[9] Curtis R. Carlson and William W. Wilmot. 2006. Innovation: The Five Disciplines for Creating What Customers Want. Crown Business, New York, NY, USA.

[10] Eric Ries. Minimum Viable Product: a guide. (August 2009). Retrieved July 29, 2020 from https://www.startuplessonslearned.com/2009/03/minimum-viableproduct.html

[11] Matthew W. Ohland, Misty L. Loughry, David J. Woehr, Lisa G. Bullard, Richard M. Felder, Cynthia J. Finelli, Richard A. Layton, Hal R. Pomeranz, and Douglas G. Schmucker. 2012. The Comprehensive Assessment of Team Member Effectiveness: Development of a Behaviorally Anchored Rating Scale for Self- and Peer Evaluation. Academy of Management Learning \& Education 11, 4 (2012), 609-630. http://www.jstor.org/stable/23412348

[12] Kenneth Reid, Tyler Hertenstein, Morgan Sperry, Debra Gallagher, and Stacy McClelland. 2013. Introducing Engineering into the Dominican Republic Classroom: Teacher Workshops. In Proceedings of the 2013 ASEE Annual Conference \& Exposition. ASEE Conferences, Atlanta, Georgia. https://peer.asee.org/19830

[13] David Reeping, John K. Estell, and Kenneth Reid. 2014. Preliminary Results of a Freshmen Capstone Project to Design Educational Modules for Teachers in the Dominican Republic. In 2014 IEEE Frontiers in Education Conference (FIE) Proceedings. IEEE, Madrid, Spain
[14] John K. Estell and David Reeping. 2015. Providing Authentic Experiences in the First Year: Designing Educational Software in Support of Service Learning Activities. In Proceedings of the 2015 ASEE Annual Conference \& Exposition. ASEE Conferences, Seattle, Washington. https://peer.asee.org/24617

[15] John K. Estell, David Reeping, and Heather Sapp. 2016. Curiosity, Connection, Creating Value: Improving Service Learning by Applying the Entrepreneurial Mindset. In Proceedings of the 2016 ASEE Annual Conference \& Exposition. ASEE Conferences, New Orleans, Louisiana. https://peer.asee.org/26621

[16] David Reeping and John K. Estell. Partnering to Develop Educational Software Applications: A Four-year Retrospective Study. In Proceedings of the 2018 ASEE Annual Conference \& Exposition. ASEE Conferences, Salt Lake City, Utah. https://peer.asee.org/30859

[17] Kappa Psi Pharmaceutical Fraternity. Retrieved July 29, 2020 from https://kappa-psi.com/

[18] Karen A. Cullen, Bridget K. Ambrose, Andrea S. Gentzke, Benjamin J. Apelberg, Ahmed Jamal, and Brian A. King. 2018. Notes from the Field: Use of Electronic Cigarettes and Any Tobacco Product Among Middle and High School Students - United States, 2011-2018. Morbidity and Mortal Weekly Report 67, 45 (November 16, 2018), 1276-1277. http://dx.doi.org/10.15585/mmwr.mm6745a5

[19] U.S. Department of Health \& Human Services. 2020. Quick Facts on the Risk of E-Cigarettes for Kids, Teens, and Young Adults. Retrieved July 29, 2020 from https://www.cdc.gov/tobacco/basic information/e-cigarettes/QuickFacts-on-the-Risks-of-E-cigarettes-for-Kids-Teens-and-Young-Adults.html

[20] John K. Estell, Susannah Howe, B. Kris Jaeger-Helton, Shraddha Sangelkar Kristoph Dietrich Kinzli, and Dustin Rand. 2019. Client Interaction Tools: Supporting Student Professionalism on Client-based Capstone Design Projects. The International fournal of Engineering Education 35, 6 (2019), 19531968.

[21] B. Kris Jaeger-Helton, Susannah Howe, and John K. Estell. 2021. Meeting the Client: Learning the Capstone Student's Perspective through the Three Intelligences Methodology. In Proceedings of the 2021 Capstone Design Conference, Dallas, Texas. (in press) http://capstonedesigncommunity.org/

[22] Jarene Fluckiger. 2010. Single Point Rubric: A Tool for Responsible Student Self-Assessment. The Delta Kappa Gamma Bulletin 76, 4 (Summer 2010), 18-25.

[23] Ann Harris Shiarella, Anne M. McCarthy, and Mary L. Tucker. 2000. Development and Construct Validity of Scores on the Community Service Attitudes Scale. Educational and Psychological Measurement 60, 2 (April 2000), 286-300.

[24] Christina A. Downey. 2013. Student Research in an Introductory Psychology Course: Outcomes of Two Experiential Learning Projects and Implications for Instruction of Human Subjects Research. The Journal of Effective Teaching 13, 2 (September 2013), 21-37. https://uncw.edu/jet/articles/vol13_2/downey.pdf

[25] E. Heidi Bauer, Barbara Moskal, Joan Gosink, Juan Lucena, and David Muñoz. 2007. Faculty and Student Attitudes toward Community Service: A Comparative Analysis. Journal of Engineering Education 96, 2 (April 2007), 129-140. https://doi.org/10.1002/j.2168-9830.2007.tb00923.x

[26] Angela Bielefeldt, Bernard Amadei, and Robyn Sandekian. 2008. Community Service Learning Attitudes of Engineering Students Engaged in Service Learning Projects. In Proceedings of the ASEE 2008 Annual Conference \& Exposition. ASEE Conferences, Pittsburgh, Pennsylvania. https://peer.asee.org/4319

[27] John K. Estell and Stephany Coffman-Wolph. 2020. Supporting Pharmaceutical Healthcare Outreach: A Culminating First-Year Programming Experience. Retrieved from https://engineeringunleashed.com/card/2455 